\title{
Periprosthetic joint infection increases the risk of one-year mortality.
}

\author{
Benjamin Zmistowski \\ Rothman Institute of Orthopedics, Thomas Jefferson University Hospital
}

Joseph A. Karam, M.D.

The Rothman Institute at Thomas Jefferson University

Joel B Durinka

Rothman Institute at Thomas Jefferson University Hospital

David S Casper, MD

Rothman Institute, Thomas Jefferson University

Javad Parvizi MD

Rothman Institute Thomas Jefferson University

Follow this and additional works at: https://jdc.jefferson.edu/rothman_institute

Part of the Orthopedics Commons

Let us know how access to this document benefits you

\section{Recommended Citation}

Zmistowski, Benjamin; Karam, M.D., Joseph A.; Durinka, Joel B; Casper, MD, David S; and Parvizi, Javad MD, "Periprosthetic joint infection increases the risk of one-year mortality." (2013).

Rothman Institute Faculty Papers. Paper 44.

https://jdc.jefferson.edu/rothman_institute/44

This Article is brought to you for free and open access by the Jefferson Digital Commons. The Jefferson Digital Commons is a service of Thomas Jefferson University's Center for Teaching and Learning (CTL). The Commons is a showcase for Jefferson books and journals, peer-reviewed scholarly publications, unique historical collections from the University archives, and teaching tools. The Jefferson Digital Commons allows researchers and interested readers anywhere in the world to learn about and keep up to date with Jefferson scholarship. This article has been accepted for inclusion in Rothman Institute Faculty Papers by an authorized administrator of the Jefferson Digital Commons. For more information, please contact: JeffersonDigitalCommons@jefferson.edu. 


\title{
Periprosthetic Joint Infection Increases the Risk of One-Year Mortality
}

\author{
Benjamin Zmistowski, BS, Joseph A. Karam, MD, Joel B. Durinka, MD, David S. Casper, BS, and Javad Parvizi, MD, FRCS \\ Investigation performed at the Rothman Institute at Thomas Jefferson University Hospital, Philadelphia, Pennsylvania
}

\begin{abstract}
Background: Periprosthetic joint infection continues to potentially complicate an otherwise successful joint replacement. The treatment of this infection often requires multiple surgical procedures associated with increased complications and morbidity. This study examined the relationship between periprosthetic joint infection and mortality and aimed to determine the effect of periprosthetic joint infection on mortality and any predictors of mortality in patients with periprosthetic joint infection.
\end{abstract}

Methods: Four hundred and thirty-six patients with at least one surgical intervention secondary to confirmed periprosthetic joint infection were compared with 2342 patients undergoing revision arthroplasty for aseptic failure. The incidence of mortality at thirty days, ninety days, one year, two years, and five years after surgery was assessed. Multivariate analysis was used to assess periprosthetic joint infection as an independent predictor of mortality. In the periprosthetic joint infection population, variables investigated as potential risk factors for mortality were evaluated.

Results: Mortality was significantly greater $(p<0.001)$ in patients with periprosthetic joint infection compared with those undergoing aseptic revision arthroplasty at ninety days (3.7\% versus $0.8 \%)$, one year (10.6\% versus $2.0 \%)$, two years (13.6\% versus $3.9 \%$ ), and five years (25.9\% versus $12.9 \%$ ). After controlling for age, sex, ethnicity, number of procedures, involved joint, body mass index, and Charlson Comorbidity Index, revision arthroplasty for periprosthetic joint infection was associated with a fivefold increase in mortality compared with revision arthroplasty for aseptic failures. In the periprosthetic joint infection population, independent predictors of mortality included increasing age, higher Charlson Comorbidity Index, history of stroke, polymicrobial infections, and cardiac disease.

Conclusions: Although it is well known that periprosthetic joint infection is a devastating complication that severely limits joint function and is consistently difficult to eradicate, surgeons must also be cognizant of the systemic impact of periprosthetic joint infection and its major influence on fatal outcome in patients.

Level of Evidence: Prognostic Level II. See Instructions for Authors for a complete description of levels of evidence.

$\mathrm{T}$ otal joint arthroplasty is currently one of the most frequently performed and most successful surgical procedures, greatly improving patient quality of life and functional status ${ }^{1,2}$. Many authors have demonstrated lower mortality rates for patients undergoing total joint ar-

Disclosure: None of the authors received payments or services, either directly or indirectly (i.e., via his or her institution), from a third party in support of any aspect of this work. One or more of the authors, or his or her institution, has had a financial relationship, in the thirty-six months prior to submission of this work, with an entity in the biomedical arena that could be perceived to influence or have the potential to influence what is written in this work. No author has had any other relationships, or has engaged in any other activities, that could be perceived to influence or have the potential to influence what is written in this work. The complete Disclosures of Potential Conflicts of Interest submitted by authors are always provided with the online version of the article. throplasty compared with those for the general population ${ }^{3-8}$. Although complications following total joint arthroplasty are infrequent, their existence continues to be a cause for concern ${ }^{9-12}$. Periprosthetic joint infection is one particularly challenging complication of total joint arthroplasty. Substantial efforts have

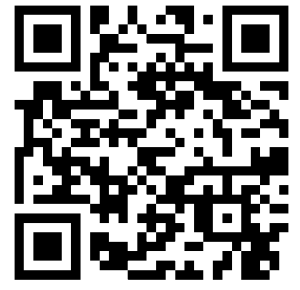

A commentary by Thomas J. Blumenfeld, MD, is linked to the online version of this article at jbjs.org. 
The Journal of Bone \& Joint SURgery $\cdot$ JBjS.org Volume 95-A · Number $24 \cdot$ December 18, 2013

Periprosthetic Joint Infection InCREases

The Risk of One-Year Mortality

TABLE I Comparison of Demographics Between Patients Undergoing Treatment for Periprosthetic Joint Infection and Those Undergoing Aseptic Revision Arthroplasty

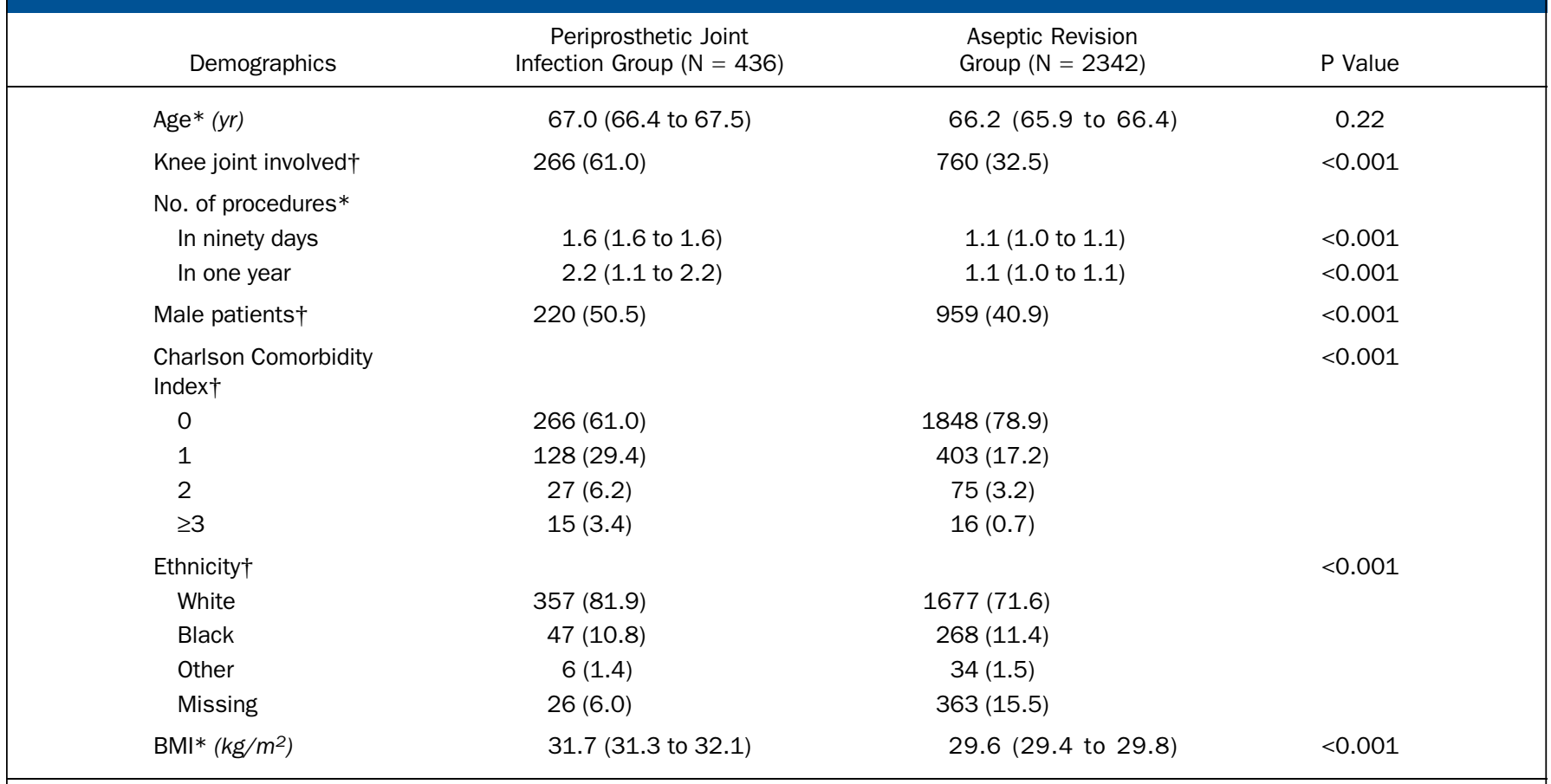

$*$ The values are given as the mean, with the $95 \%$ confidence interval in parentheses. $\dagger$ The values are given as the number of patients, with the percentage in parentheses.

been made to prevent this complication by implementing numerous strategies that include antibiotic prophylaxis, patient risk stratification, detection and treatment of Staphylococcus aureus colonization, and clean operating room environment, among others ${ }^{11,13,14}$. Despite the introduction of these methods, the risk of infection after total joint arthroplasty remains approximately $1 \%^{11,15-17}$. In recent studies, Bozic et al. observed that infection was the third most common indication for revision hip arthroplasty (14.7\% of cases) and the most common cause for failure of total knee arthroplasty $(25.2 \%$ of (ases) $)^{18,19}$.

The risk factors for developing periprosthetic joint infection following total joint arthroplasty include male sex, advanced age, higher body mass index (BMI), and presence of comorbidities (especially cardiac conditions) $)^{11,15,20-25}$. These factors are also associated with early mortality following total joint arthroplasty ${ }^{24-28}$, suggesting that periprosthetic joint infection would be associated with an increased risk of mortality. The disease process of periprosthetic joint infection itself may also lead to an increase in mortality, as experienced in other fields, through the potential development of fatal bacteremia ${ }^{29-31}$. Additionally, the need for aggressive and often multiple surgical treatments, long-term inpatient stays, and long-term use of systemic antibiotics to treat periprosthetic joint infection would be expected to alter life expectancy ${ }^{32-34}$.

With the projected increase in the numbers of total joint arthroplasties, specifically revision arthroplasties, the burden of periprosthetic joint infection is expected to rise ${ }^{15,35}$. Hence, a complete understanding of the effect that this disease may have on quality and longevity of life is important. Therefore, this study aimed to determine the impact of periprosthetic joint infection on life expectancy and to identify any factors that predict increased mortality rates after treatment for periprosthetic joint infection.

\section{Materials and Methods}

fter obtaining institutional review board approval, a retrospective study $\mathrm{A}_{\text {was undertaken. Patients undergoing revision hip or knee arthroplasty }}$ from January 2000 through March 2010 were identified utilizing the institutional database. This provided 2955 patients who underwent revision joint arthroplasty. This sample included $613(20.7 \%)$ who were suspected of having periprosthetic joint infection. Complete data related to the workup for periprosthetic joint infection, including erythrocyte sedimentation rate (ESR) and serum C-reactive protein (CRP) concentration, synovial fluid analysis and culture, tissue culture, and joint presentation, were collected. Utilizing these data, a diagnosis of periprosthetic joint infection was confirmed or was excluded on the basis of the definition of periprosthetic joint infection provided by the Musculoskeletal Infection Society ${ }^{36}$. As histological analysis is not performed at this institution, the definition was modified to require a sinus tract, two separate positive cultures with phenotypically identical organisms, or three of the following: elevated ESR and CRP, elevated synovial white blood cell count, elevated synovial fluid polymorphonuclear neutrophil (PMN) percentage, intra-articular purulence, and a single positive culture. The threshold was $30 \mathrm{~mm}$ per hour for ESR, $10 \mathrm{mg}$ per liter for CRP, 3000 cells per microliter for the synovial white blood cell count, and $75 \%$ for the synovial PMN percentage ${ }^{37-39}$. A diagnosis of periprosthetic joint infection was confirmed in 436 patients, leaving 2342 patients in the aseptic cohort. 
The Journal of Bone \& Joint Surgery $\cdot$ JBjS. Org Volume 95-A · Number $24 \cdot$ DeCEMBer 18,2013

Periprosthetic Joint Infection InCREases

THE Risk OF ONE-YEAR MORTALity

\section{TABLE II Survival Over Varying Time Periods Following Initial Treatment for Periprosthetic Joint Infection Versus Aseptic Failure for Patients with Available Follow-up for the Maximum Time of the Period}

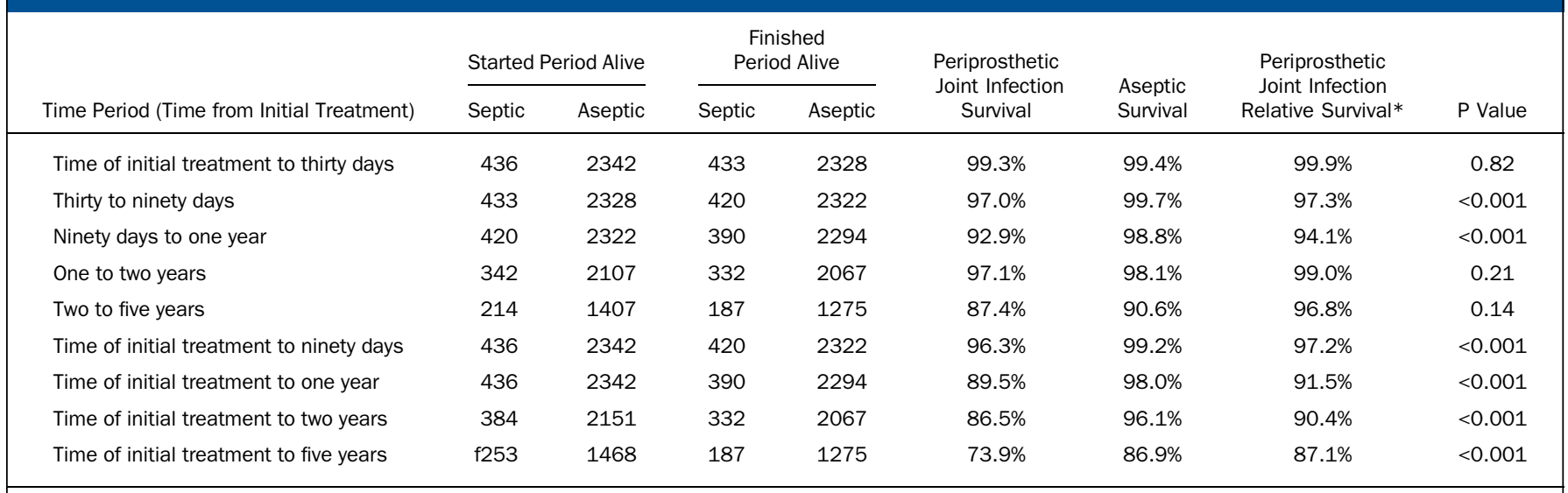

*The relative survival for periprosthetic joint infection, the survival attributable to the periprosthetic joint infection diagnosis (after adjusting for the aseptic control), decreases over time, with the most significant decreases occurring in the first year.

To ascertain the deceased patients in this cohort, a Social Security number or other identifiers were used to search the Social Security Death Index. If the patient had died, the date of death was recorded. Mortality incidence within thirty days, ninety days, one year, two years, and five years of admission was calculated. The time until death was calculated as the amount of time elapsing from the initial surgical intervention for joint failure (revision) to the date of death. For calculating mortality at thirty days, ninety days, and one year, the entire cohort was utilized, as the minimum time frame from admission to the mortality search was eighteen months. To maintain a minimum buffer of six months between the desired follow-up length and the mortality search, the cohort was limited to all patients with an initial arthroplasty date prior to April 1, 2009, when calculating the two-year death incidence; this provided a minimum of thirty months between mortality search and admission. Similarly, the cohort was limited to admissions prior to April 1, 2006, when calculating the five-year death incidence. Patients undergoing aseptic revision were used as a control group. If an association between periprosthetic joint infection and mortality was observed, attempts to further quantify this risk were made

\section{TABLE III Multivariate Logistic Regression Comparing Mortality and Variables for Four Models}

\begin{tabular}{|c|c|c|c|c|c|c|c|c|}
\hline Variables & \multicolumn{2}{|c|}{ Model $1 *(N=2778)$} & \multicolumn{2}{|c|}{ Model $2 \nmid(\mathrm{N}=2778)$} & \multicolumn{2}{|c|}{ Model $3 \neq(N=2778)$} & \multicolumn{2}{|c|}{ Model $4 \S(N=2375)$} \\
\hline $\begin{array}{l}\text { Periprosthetic joint } \\
\text { infection diagnosis }\end{array}$ & $5.6(3.7-8.6)$ & $<0.001$ & $6.0(3.9-9.2)$ & $<0.001$ & $5.6(3.4-9.2)$ & $<0.001$ & $5.9(3.5-10.2)$ & $<0.001$ \\
\hline Age & & & $1.1(1.1-1.1)$ & $<0.001$ & $1.1(1.1-1.1)$ & $<0.001$ & $1.1(1.1-1.1)$ & $<0.001$ \\
\hline Male sex & & & & & $1.7(1.1-2.7)$ & 0.02 & $1.6(1.0-2.6)$ & 0.06 \\
\hline Knee joint involved & & & & & $0.9(0.6-1.5)$ & 0.69 & $0.8(0.5-1.4)$ & 0.43 \\
\hline Procedures in ninety days & & & & & $0.8(0.5-1.1)$ & 0.17 & $0.8(0.5-1.2)$ & 0.32 \\
\hline Ethnicity & & & & & NAT† & 0.84 & NA†† & 0.82 \\
\hline Black (versus white) & & & & & $1.0(0.5-2.3)$ & 0.96 & $0.8(0.4-2.1)$ & 0.76 \\
\hline Other (versus white) & & & & & $0.3(0.0-6.5)$ & 0.48 & $0.4(0.0-7.6)$ & 0.56 \\
\hline
\end{tabular}


The Journal of Bone \& Joint Surgery $\cdot$ JBJS.org Volume 95-A · Number 24 DeCember 18,2013

Periprosthetic Joint Infection Increases

THE Risk of One-Year Mortality

TABLE IV Bivariate Analysis of Potential Predictors of Mortality in the First Year After Treatment for Periprosthetic Joint Infection

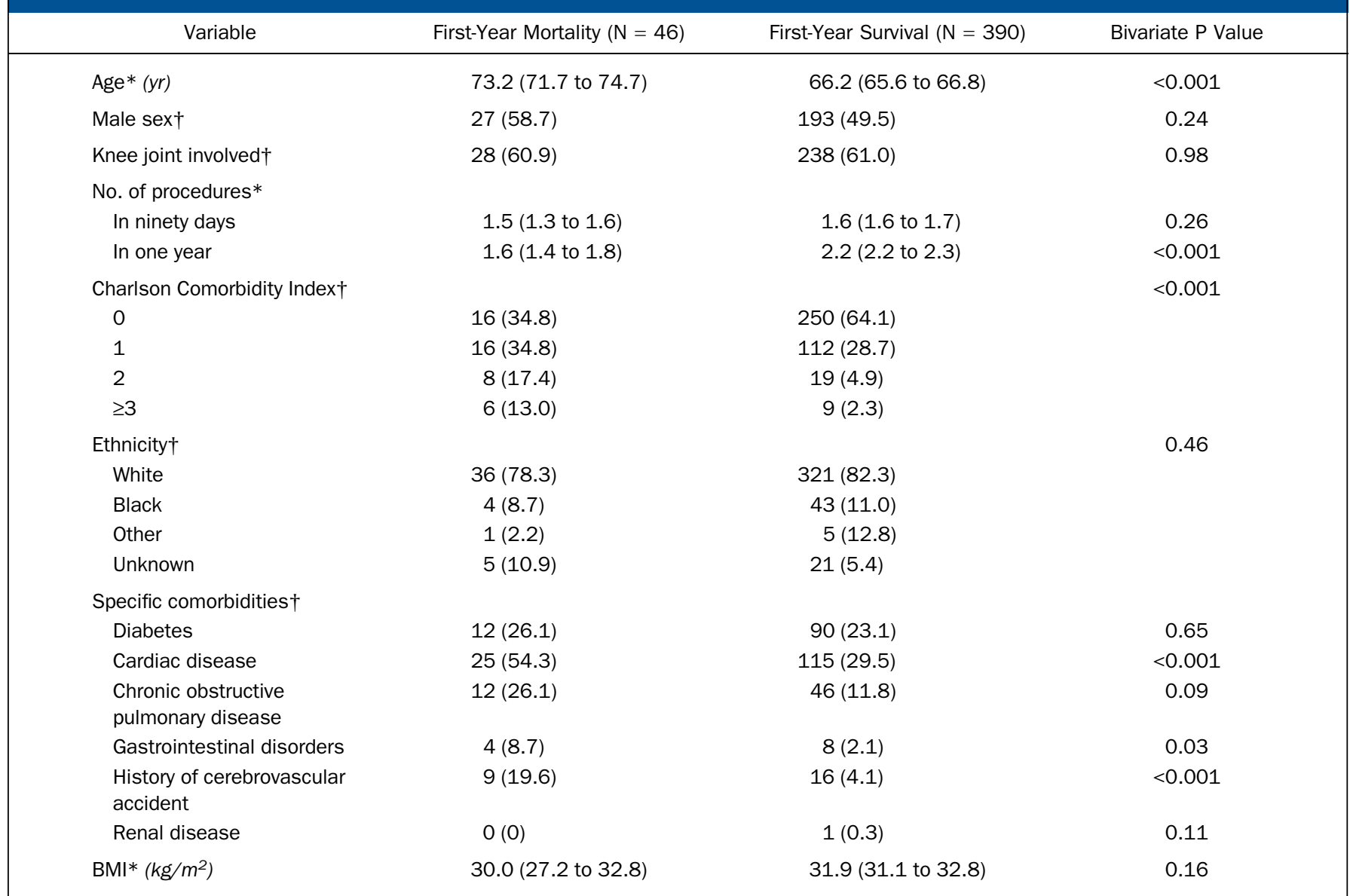

$*$ The values are given as the mean, with the $95 \%$ confidence interval in parentheses. $\uparrow$ The values are given as the number of patients, with the percentage in parentheses.

by controlling for other potential predictors of mortality. These predictors included sex, age, ethnicity, number of joint-related procedures, BMI, and Charlson Comorbidity Index. The Charlson Comorbidity Index provides a method of quantifying overall health and is predictive of mortality ${ }^{40}$. For this analysis, the Dartmouth-Manitoba adaptation was used to calculate the Charlson Comorbidity Index and was not adjusted for age ${ }^{41}$. The number of joint-related procedures was gathered from the institutional database and was limited to the total number of procedures performed on a lowerextremity joint within one year of the initial treatment. The null hypothesis was that periprosthetic joint infection would not impact mortality in this cohort.

Another goal of this study was to identify any factors that predicted oneyear mortality in patients with periprosthetic joint infection. Factors investigated included age, sex, ethnicity, number of procedures, Charlson Comorbidity Index, specific comorbidities, and infecting organism. Specific comorbidities were related to cardiac disorder, respiratory disorder, gastrointestinal disorder, neurologic disorder, or diabetes ${ }^{42}$. Infecting organisms were assessed for each periprosthetic joint infection admission and were aggregated taxonomically. The null hypothesis was that none of the tested variables would predict mortality in the cohort treated for periprosthetic joint infection.

To test the null hypotheses, bivariate analysis was performed. This consisted of the Student $t$ test for continuous variables and the chi-square test (number of events greater than ten) or Fisher exact test (lower event size) for categorical variables. Multivariate analysis was then performed to ascertain independent predictors of the studied outcome if a sufficient event size existed. Multivariable analysis for the entire cohort was performed with a logistic regression, including all potential variables in a pseudo-stepwise manner: first including only periprosthetic joint infection, then including periprosthetic joint infection and age, then including all variables except BMI, and finally including all potential predictors of mortality. BMI was excluded in the third model, as this variable was only available in 2375 $(85.5 \%)$ of the 2778 cases. Subsequently, multivariable analysis was performed on the periprosthetic joint infection cohort to determine independent predictors of mortality in this cohort.

\section{Source of Funding}

No external funds were received for the performance of this research.

\section{Results}

$\mathrm{n}$ this cohort, the incidence of mortality for all patients was $10.6 \%$ (seventeen of 2778 ) within thirty days, $1.3 \%$ (thirty-six of 2778 ) within ninety days, $3.4 \%$ (ninety-four of 2778 ) within one year, $5.4 \%$ (136 of 2535) within two years, and 15.0\% (259 of 1721) within five years. Patients with periprosthetic joint 
The Journal of Bone \& Joint SURgery • JBJS. Org Volume 95-A · Number $24 \cdot$ December 18, 2013

Periprosthetic Joint Infection Increases

The Risk of One-Year Mortality

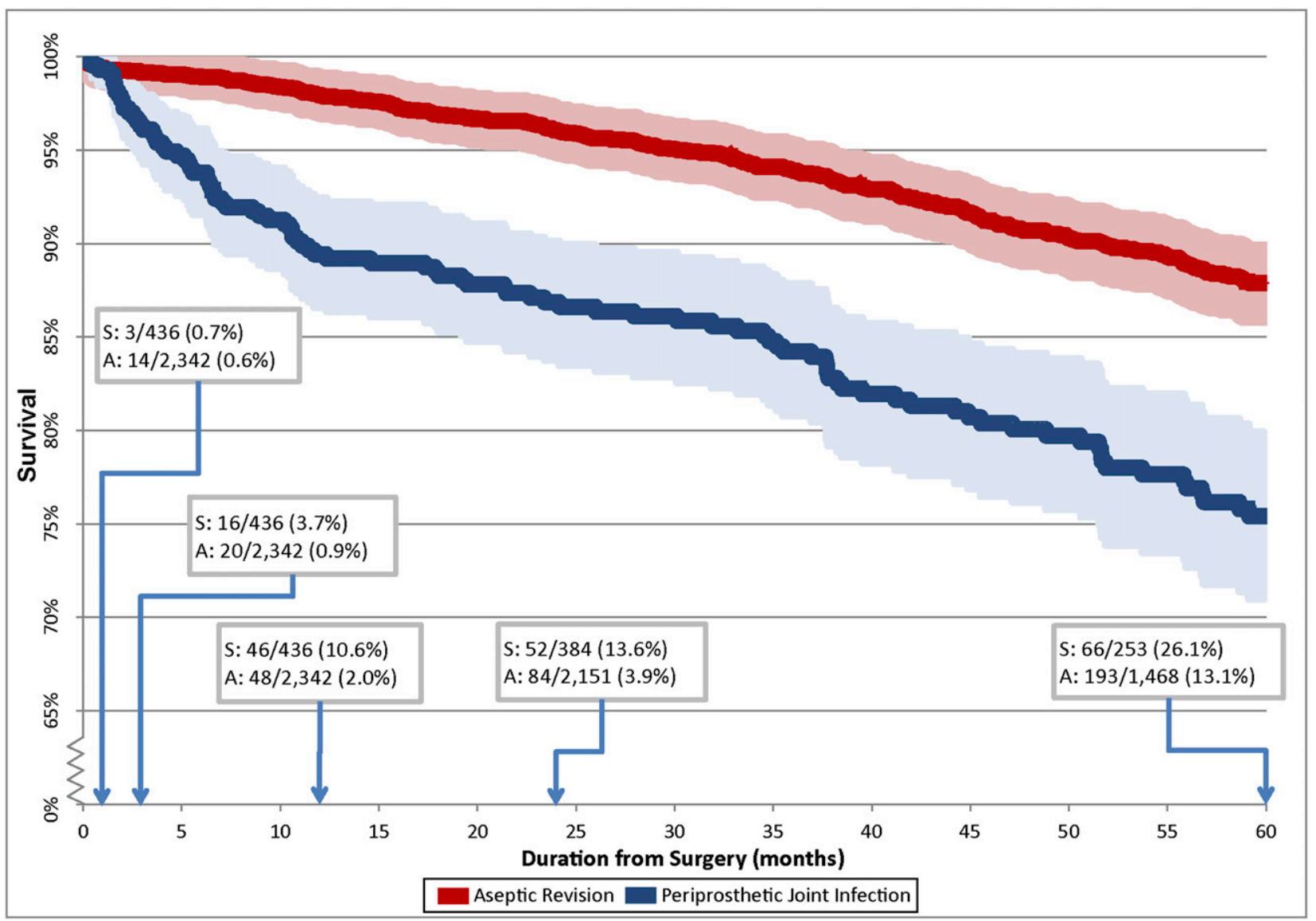

Fig. 1

Kaplan-Meier survival curve with 95\% confidence intervals for five years from first admission for patients undergoing revision arthroplasty.

The analysis is separated into patients undergoing treatment for periprosthetic joint infection or aseptic failure. Vertical marks indicate censoring. At established time points (thirty days, ninety days, one year, two years, and five years), the mortality incidence in all patients available for analysis at that time point is displayed. $\mathrm{A}=$ patients undergoing aseptic revision, and $\mathrm{S}=$ patients undergoing septic revision.

infection had similar age, but were more likely male, had elevated age-unadjusted Charlson Comorbidity Index, were more likely undergoing knee revision arthroplasty, and had a greater number of joint-related procedures compared with patients undergoing aseptic revision surgery (Table I). Mortality was significantly greater $(\mathrm{p}<0.001)$ in patients with periprosthetic joint infection than in patients undergoing aseptic revision at the ninety-day, one-year, two-year, and five-year time points (Fig. 1). When assessing each individual time period, the mortality incidence was significantly greater $(\mathrm{p}<0.001)$ in patients with periprosthetic joint infection from thirty to ninety days and from ninety days to one year (Table II). Also, the relative fiveyear survival rate in patients with periprosthetic joint infection was $87.3 \%$. Furthermore, periprosthetic joint infection was a predictor of one-year mortality when adjusting only for age; when adjusting for ethnicity, age, sex, number of procedures within ninety days, joint, and Charlson Comorbidity Index; and when adjusting for all variables (Table III), including BMI, rejecting the null hypothesis.

Advanced age $(\mathrm{p}<0.001)$, increased Charlson Comorbidity Index $(\mathrm{p}<0.001)$, cardiac disease $(\mathrm{p}<0.001)$, gastro- intestinal disorders $(p=0.03)$, and history of cerebrovascular accident $(p<0.001)$ were significant predictors of mortality in patients with periprosthetic joint infection in bivariate analysis (Table IV). No significant difference in mortality was observed between patients with hip infections and those with knee infections. Infections caused by gram-negative organisms resulted in a one-year mortality rate of $19.3 \%$ (eleven of fifty-seven) compared with $9.2 \%$ (thirty-five of 379 ) in periprosthetic joint infection cases without gram-negative organisms $(p=0.02)$ (see Appendix). For major taxonomic groups, multiple trends were evident, including significantly increased mortality $(\mathrm{p}=$ 0.08 ) in patients who had periprosthetic joint infection due to methicillin-resistant S. aureus (MRSA) (15.9\% [thirteen of eighty-two]) compared with patients who had periprosthetic joint infection due to methicillin-sensitive S. aureus (MSSA) (7.4\% [seven of ninety-five]). When performing multivariate analysis, age, number of surgical procedures in the first year, Charlson Comorbidity Index, cardiac disease, history of stroke, and polymicrobial infections were independent predictors of one-year mortality in patients with periprosthetic joint infection (Table V). 
The Journal of Bone \& Joint Surgery $\cdot$ Jbjs.org Volume 95-A - Number 24 - December 18, 2013
Periprosthetic Joint Infection Increases

THE Risk of ONE-Year Mortality

\begin{tabular}{|c|c|c|}
\hline Variable & Odds Ratio* & $P$ Value \\
\hline Age & 1.1 (1.0 to 1.1$)$ & 0.001 \\
\hline Male sex & $2.3(1.0$ to 5.3$)$ & 0.05 \\
\hline Knee joint involved & 1.5 (0.6 to 3.6$)$ & 0.35 \\
\hline \multicolumn{3}{|l|}{ No. of procedures } \\
\hline In ninety days & 2.5 (0.9 to 7.0 ) & 0.09 \\
\hline In one year & 0.3 (0.1 to 0.8$)$ & 0.01 \\
\hline Charlson Comorbidity Index & $1.6(1.2$ to 2.1$)$ & 0.001 \\
\hline \multicolumn{3}{|l|}{ Ethnicity } \\
\hline Black (versus white) & 1.5 (0.4 to 6.4$)$ & 0.56 \\
\hline Other (versus white) & 0.6 (0.0 to 14.6$)$ & 0.74 \\
\hline Unknown (versus white) & $2.2(0.5$ to 9.2$)$ & 0.27 \\
\hline \multicolumn{3}{|l|}{ Comorbidities } \\
\hline Diabetes & 0.5 (0.2 to 1.3$)$ & 0.15 \\
\hline Cardiac disease & 2.7 (1.1 to 6.3$)$ & 0.03 \\
\hline $\begin{array}{l}\text { Chronic obstructive } \\
\text { pulmonary disease }\end{array}$ & 2.5 (0.9 to 7.0$)$ & 0.09 \\
\hline Gastrointestinal disorders & 2.8 (0.5 to 15.3$)$ & 0.23 \\
\hline $\begin{array}{l}\text { History of cerebrovascular } \\
\text { accident }\end{array}$ & 3.6 (1.0 to 12.7$)$ & 0.05 \\
\hline Renal disease & $0.0(0.0$ to 0.0$)$ & 1.0 \\
\hline BMI & $1.0(1.0$ to 1.1$)$ & 0.48 \\
\hline \multicolumn{3}{|l|}{ Infecting organism } \\
\hline Gram-positive & 0.1 (0.0 to 1.2 ) & 0.06 \\
\hline Staphylococcus & $1.7(0.0$ to 75.3$)$ & 0.78 \\
\hline $\begin{array}{l}\text { Methicillin-sensitive } \\
\text { S. aureus }\end{array}$ & 1.1 (0.1 to 21.4$)$ & 0.97 \\
\hline $\begin{array}{l}\text { Methicillin-resistant } \\
\text { S. aureus }\end{array}$ & $1.5(0.1$ to 5.3$)$ & 0.79 \\
\hline $\begin{array}{l}\text { Coagulase-negative } \\
\text { Staphylococcus }\end{array}$ & 0.7 (0.0 to 14.3$)$ & 0.84 \\
\hline Streptococcus & 1.1 (0.1 to 10.8$)$ & 0.97 \\
\hline Gram-negative & 0.3 (0.0 to 2.9 ) & 0.31 \\
\hline Polymicrobial & 6.3 (1.3 to 30.8$)$ & 0.02 \\
\hline Culture-negative & 0.1 (0.0 to 1.4$)$ & 0.09 \\
\hline
\end{tabular}

\section{Discussion}

Deriprosthetic joint infection remains a major complication of total joint arthroplasty ${ }^{43}$. The outcome following treatment for periprosthetic joint infection ranges from a return to full function to the possible need for amputation or arthrodesis ${ }^{33,41,44,45}$. Of rising concern throughout the joint replacement community is infection involving MRSA, as it is often resistant to aggressive treatment, resulting in suboptimal outcome ${ }^{46-49}$. Additionally, patient health status has been implicated in predicting the outcome of periprosthetic joint infection treatment ${ }^{50}$. This study investigated the impact of periprosthetic joint infection on mortality and the predictors of mortality in patients with periprosthetic joint infection.

There was a significant increase in mortality in patients undergoing surgical intervention for periprosthetic joint infection compared with patients undergoing aseptic revision arthroplasty. Periprosthetic joint infection increased the risk of death more than fivefold when controlling for other potential confounding variables. McGarry et al. reported a fivefold increase in the ninety-day mortality risk after surgical site infection in an elderly population undergoing various surgical procedures $^{30}$. This is similar to the fivefold increase in the unadjusted mortality risk at ninety days found for patients with periprosthetic joint infection. Interestingly, the effect of periprosthetic joint infection on mortality is greatest between thirty days and one year, with no statistical difference in mortality between one and five years. Despite this, the relative survival rate of patients with periprosthetic joint infection compared with those requiring aseptic revision was $87.3 \%$ at five years. For comparison, the five-year relative survival rates for the top five most common cancers are $99 \%$ for prostate cancer, $89 \%$ for breast cancer, $16 \%$ for lung and bronchial cancer, $64 \%$ for colorectal cancer, and $91 \%$ for melanoma ${ }^{51}$. The effect of periprosthetic joint infection on patient mortality within thirty days is inconclusive, possibly stemming from a type-II error or an indication that no difference exists in the initial insult required in treating periprosthetic joint infection compared with aseptic failure. Other authors have provided anecdotal evidence of increased mortality in patients receiving treatment for periprosthetic joint infection $^{52-54}$. Most recently, Berend et al. reported $4 \%$ mortality within ninety days $\mathrm{s}^{52}$. Previously identified risk factors for periprosthetic joint infection include male sex, advanced age, increased BMI, increased number of comorbidities, and knee arthroplasty, among others ${ }^{11,15,20-23}$. Many risk factors are also associated with an increased risk of mortality, implying that the association between mortality and periprosthetic joint infection is secondary to poor health status. However, after adjusting for such factors, periprosthetic joint infection remained a significant predictor of mortality, suggesting that the disease process or the treatment itself contributes to the increased risk of death.

Independent predictors of first-year mortality were advanced age, increased Charlson Comorbidity Index, cardiac disease, and history of cerebrovascular accident. In multivariate analysis, the number of procedures within one year had a protective effect on mortality. Although surgical intervention carries the risk of death, the number of procedures was likely protective because it signaled that patients had a level of health allowing for repeated surgical intervention. From a microbiological standpoint, patients with multiple organisms on culture, MRSA, and gram-negative organisms had increased first-year mortality. Marculescu and Cantey found that patient age greater than sixty-five years was an independent risk factor for polymicrobial periprosthetic joint infection compared with monomicrobial periprosthetic joint infection, which may account for the moderate increase in mortality ${ }^{55}$. However, polymicrobial infections were a predictor of mortality independent of age and overall 
The Journal of Bone \& Joint Surgery - Jbjs.org Volume 95-A · Number 24 - December 18, 2013
Periprosthetic Joint Infection Increases

The Risk of One-Year Mortality health, suggesting another mechanism by which polymicrobial infections predispose to early death. Gram-negative infections are also expected to be associated with poor overall health. This is evident in an analysis of success in treating gram-negative periprosthetic joint infection at this institution, where the current authors (B.Z. and J.P.) found that a large proportion of patients (26\% [six of twenty-three]) did not complete a twostage exchange because of death ${ }^{53}$. Lastly, MRSA is a particularly virulent organism that can cause persistent periprosthetic joint infection and increased cost of treatment $t^{49,53,56}$. Evidence provided by Nixon et al. demonstrated that, following femoral fracture and admission to an orthopaedic ward, infection with MRSA doubled the risk of first-year mortality ${ }^{31}$. Similarly, Leung et al. reported that $24 \%$ of patients receiving treatment for periprosthetic joint infection due to MRSA had died at a mean follow-up of nearly five years ${ }^{54}$. The current study also found a trend of MRSA predicting mortality, and MRSA has once again been proven to predict a dismal outcome.

The limitations of this study included its retrospective nature and reliance upon an electronic database to identify patients and other factors investigated. However, the Social Security Death Index has been validated as a tool for identifying deceased patients $s^{57}$. In attempts to mitigate the inaccuracy of periprosthetic joint infection classification, all periprosthetic joint infection cases were confirmed with use of a stringent and recently proposed standard definition for periprosthetic joint infection $^{36}$. However, because not all variables were available for this analysis, it was necessary to eliminate the cases that could not be confirmed, limiting our study cohort and likely eliminating some cases of true periprosthetic joint infection that had negative cultures. Furthermore, this definition cannot be used in patients not requiring surgical intervention as it includes tissue specimen for culture, joint appearance, and histological analysis in its defining criteria. Thus, this analysis is limited to only the patients with periprosthetic joint infection who underwent surgical treatment. Additionally, operative variables such as operative time and blood loss were not reliably available for the entire cohort and were not reported. However, we do not believe that this weakens the findings, as the mortality rate of patients with periprosthetic joint infection was no different in the early postoperative period (thirty days) compared with the control group. Attempts were made to determine whether periprosthetic joint infection is an independent predictor of mortality by controlling for age, sex, ethnicity, number of surgical procedures, involved joint, BMI, and Charlson Comorbidity Index. Although it is believed that this adjustment sufficiently accounts for differences between the cohorts, it is not possible to identify all potential predictors of mortality that may vary between the groups.

In conclusion, undergoing treatment for periprosthetic joint infection significantly and independently increases the risk of mortality. It is evident that increased risk of mortality is due to a direct adverse effect of periprosthetic joint infection, as well as the fact that periprosthetic joint infection is a reflection of a decreased health status. Thus, in addition to the many efforts invested to control infection in patients diagnosed with periprosthetic joint infection, it is paramount to also ensure a tight control of the chronic diseases.

\section{Appendix}

eA A table comparing the infecting organism between paeA tients who died and those who survived the first year following treatment is available with the online version of this article as a data supplement at jbjs.org.

Note: We are grateful to Mitchell Maltenfort, PhD, for his assistance with statistical analysis.

Benjamin Zmistowski, BS

Joseph A. Karam, MD

Joel B. Durinka, MD

David S. Casper, BS

Javad Parvizi, MD, FRCS

Rothman Institute at Thomas Jefferson University Hospital, 925 Chestnut Street, 5th Floor,

Philadelphia, PA 19107.

E-mail address for J. Parvizi: research@rothmaninstitute.net

\section{References}

1. Ethgen $O$, Bruyère $O$, Richy $F$, Dardennes $C$, Reginster JY. Health-related quality of life in total hip and total knee arthroplasty. A qualitative and systematic review of the literature. J Bone Joint Surg Am. 2004 May;86(5):963-74.

2. Learmonth ID, Young $C$, Rorabeck $C$. The operation of the century: total hip replacement. Lancet. 2007 Oct 27;370(9597):1508-19.

3. Barrett J, Losina E, Baron JA, Mahomed NN, Wright J, Katz JN. Survival following total hip replacement. J Bone Joint Surg Am. 2005 Sep;87(9): 1965-71.

4. Lie SA, Engesaeter LB, Havelin LI, Gjessing HK, Vollset SE. Mortality after total hip replacement: 0-10-year follow-up of 39,543 patients in the Norwegian Arthroplasty Register. Acta Orthop Scand. 2000 Feb;71(1):19-27.

5. Paavolainen $P$, Pukkala E, Pulkkinen $P$, Visuri T. Causes of death after total hip arthroplasty: a nationwide cohort study with 24,638 patients. J Arthroplasty. 2002 Apr;17(3):274-81.

6. Ritter MA, Albohm MJ, Keating EM, Faris PM, Meding JB. Life expectancy after total hip arthroplasty. J Arthroplasty. 1998 Dec;13(8):874-5.

7. Robertsson 0 , Stefánsdóttir A, Lidgren L, Ranstam J. Increased long-term mortality in patients less than 55 years old who have undergone knee replacement for osteoarthritis: results from the Swedish Knee Arthroplasty Register. J Bone Joint Surg Br. 2007 May;89(5):599-603.
8. Whittle J, Steinberg EP, Anderson GF, Herbert R, Hochberg MC. Mortality after elective total hip arthroplasty in elderly Americans. Age, gender, and indication for surgery predict survival. Clin Orthop Relat Res. 1993 Oct;(295):119-26.

9. Cullen C, Johnson DS, Cook G. Re-admission rates within 28 days of total hip replacement. Ann R Coll Surg Engl. 2006 Sep;88(5):475-8.

10. Kurtz SM, Ong KL, Schmier J, Mowat F, Saleh K, Dybvik E, Kärrholm J, Garellick G, Havelin LI, Furnes O, Malchau H, Lau E. Future clinical and economic impact of revision total hip and knee arthroplasty. J Bone Joint Surg Am. 2007 Oct;89(Suppl 3): 144-51.

11. Pulido L, Ghanem E, Joshi A, Purtill JJ, Parvizi J. Periprosthetic joint infection: the incidence, timing, and predisposing factors. Clin Orthop Relat Res. 2008 Jul;466(7):1710-5. Epub 2008 Apr 18.

12. Pulido L, Parvizi J, Macgibeny M, Sharkey PF, Purtill JJ, Rothman RH, Hozack WJ. In hospital complications after total joint arthroplasty. J Arthroplasty. 2008 Sep;23(6)(Suppl 1):139-45.

13. Garvin KL, Hanssen AD. Infection after total hip arthroplasty. Past, present, and future. J Bone Joint Surg Am. 1995 Oct;77(10):1576-88.

14. Rao N, Cannella BA, Crossett LS, Yates AJ Jr, McGough RL 3rd, Hamilton CW. Preoperative screening/decolonization for Staphylococcus aureus to prevent 
The Journal of Bone \& Joint Surgery $\cdot$ Jbjs.org Volume 95-A · Number 24 - December 18, 2013
Periprosthetic Joint Infection Increases

The Risk of ONE-Year Mortality orthopedic surgical site infection: prospective cohort study with 2-year follow-up. J Arthroplasty. 2011 Dec;26(8):1501-7. Epub 2011 Apr 19.

15. Kurtz SM, Lau E, Schmier J, Ong KL, Zhao K, Parvizi J. Infection burden for hip and knee arthroplasty in the United States. J Arthroplasty. 2008 Oct;23(7):984-91. Epub 2008 Apr 10.

16. Mahomed NN, Barrett JA, Katz JN, Phillips CB, Losina E, Lew RA, Guadagnoli E, Harris WH, Poss R, Baron JA. Rates and outcomes of primary and revision total hip replacement in the United States Medicare population. J Bone Joint Surg Am. 2003 Jan;85(1):27-32.

17. Phillips JE, Crane TP, Noy M, Elliott TSJ, Grimer RJ. The incidence of deep prosthetic infections in a specialist orthopaedic hospital: a 15-year prospective survey. J Bone Joint Surg Br. 2006 Jul;88(7):943-8.

18. Bozic KJ, Kurtz SM, Lau E, Ong K, Chiu V, Vail TP, Rubash HE, Berry DJ. The epidemiology of revision total knee arthroplasty in the United States. Clin Orthop Relat Res. 2010 Jan;468(1):45-51. Epub 2009 Jun 25.

19. Bozic KJ, Kurtz SM, Lau E, Ong K, Vail TP, Berry DJ. The epidemiology of revision total hip arthroplasty in the United States. J Bone Joint Surg Am. 2009 Jan;91(1):128-33.

20. Berbari EF, Hanssen AD, Duffy MC, Steckelberg JM, Ilstrup DM, Harmsen WS, Osmon DR. Risk factors for prosthetic joint infection: case-control study. Clin Infect Dis. 1998 Nov; $27(5): 1247-54$

21. Bozic KJ, Ries MD. The impact of infection after total hip arthroplasty on hospital and surgeon resource utilization. J Bone Joint Surg Am. 2005 Aug;87(8):1746-51. 22. Panvizi J, Pulido L, Purtill JJ, Mraovic B, Sharkey PF, Hozak WJ, Rothman RH. Metabolic syndrome increases the risk for pulmonary embolism after joint arthroplasty. J Arthroplasty. 2008;23(2):327.

23. Peel TN, Dowsey MM, Daffy JR, Stanley PA, Choong PFM, Buising KL. Risk factors for prosthetic hip and knee infections according to arthroplasty site. J Hosp Infect. 2011 Oct;79(2):129-33. Epub 2011 Aug 6.

24. Bozic KJ, Lau E, Kurtz S, Ong K, Rubash H, Vail TP, Berry DJ. Patient-related risk factors for periprosthetic joint infection and postoperative mortality following total hip arthroplasty in Medicare patients. J Bone Joint Surg Am. 2012 May 2;94(9):794-800.

25. Bozic KJ, Lau E, Kurtz S, Ong K, Berry DJ. Patient-related risk factors for postoperative mortality and periprosthetic joint infection in medicare patients undergoing TKA. Clin Orthop Relat Res. 2012 Jan;470(1):130-7.

26. Parvizi J, Johnson BG, Rowland C, Ereth MH, Lewallen DG. Thirty-day mortality after elective total hip arthroplasty. J Bone Joint Surg Am. 2001 Oct;83(10):1524-8. 27. Seagroatt V, Tan HS, Goldacre M, Bulstrode C, Nugent I, Gill L. Elective total hip replacement: incidence, emergency readmission rate, and postoperative mortality. BMJ. 1991 Dec 7;303(6815):1431-5.

28. Turrentine FE, Hanks JB, Schirmer BD, Stukenborg GJ. The relationship between body mass index and 30-day mortality risk, by principal surgical procedure. Arch Surg. 2012 Mar;147(3):236-42. Epub 2011 Nov 21.

29. Cosgrove SE, Sakoulas G, Perencevich EN, Schwaber MJ, Karchmer AW, Carmeli Y. Comparison of mortality associated with methicillin-resistant and methicillin-susceptible Staphylococcus aureus bacteremia: a meta-analysis. Clin Infect Dis. 2003 Jan 1;36(1):53-9. Epub 2002 Dec 13.

30. McGarry SA, Engemann JJ, Schmader K, Sexton DJ, Kaye KS. Surgical-site infection due to Staphylococcus aureus among elderly patients: mortality, duration of hospitalization, and cost. Infect Control Hosp Epidemiol. 2004 Jun;25(6):461-7. 31. Nixon $M$, Jackson $B$, Varghese $P$, Jenkins $D$, Taylor G. Methicillin-resistant Staphylococcus aureus on orthopaedic wards: incidence, spread, mortality, cost and control. J Bone Joint Surg Br. 2006 Jun;88(6):812-7.

32. Kraay MJ, Goldberg VM, Fitzgerald SJ, Salata MJ. Cementless two-staged total hip arthroplasty for deep periprosthetic infection. Clin Orthop Relat Res. 2005 Dec;441:243-9.

33. Toms AD, Davidson D, Masri BA, Duncan CP. The management of peri-prosthetic infection in total joint arthroplasty. J Bone Joint Surg Br. 2006 Feb;88(2):149-55.

34. Zimmerli W, Ochsner PE. Management of infection associated with prosthetic joints. Infection. 2003 Mar;31(2):99-108.

35. Kurtz S, Ong K, Lau E, Mowat F, Halpern M. Projections of primary and revision hip and knee arthroplasty in the United States from 2005 to 2030. J Bone Joint Surg Am. 2007 Apr;89(4):780-5.
36. Parvizi J, Zmistowski B, Berbari EF, Bauer TW, Springer BD, Della Valle CJ, Garvin KL, Mont MA, Wongworawat MD, Zalavras CG. New definition for periprosthetic joint infection: from the Workgroup of the Musculoskeletal Infection Society. Clin Orthop Relat Res. 2011 Nov:469(11):2992-4.

37. Ghanem E, Parvizi J, Burnett RSJ, Sharkey PF, Keshavarzi N, Aggarwal A, Barrack RL. Cell count and differential of aspirated fluid in the diagnosis of infection at the site of total knee arthroplasty. J Bone Joint Surg Am. 2008 Aug;90(8):1637-43.

38. Zmistowski B, Restrepo C, Huang R, Hozack WJ, Parvizi J. Periprosthetic joint infection diagnosis: a complete understanding of white blood cell count and differential. J Arthroplasty. 2012 Oct;27(9):1589-93. Epub 2012 Apr 28.

39. Schinsky MF, Della Valle CJ, Sporer SM, Paprosky WG. Perioperative testing for joint infection in patients undergoing revision total hip arthroplasty. J Bone Joint Surg Am. 2008 Sep;90(9):1869-75.

40. Charlson ME, Pompei P, Ales KL, MacKenzie CR. A new method of classifying prognostic comorbidity in longitudinal studies: development and validation.

J Chronic Dis. 1987;40(5):373-83.

41. Romano PS, Roos LL, Jollis JG. Adapting a clinical comorbidity index for use with ICD-9-CM administrative data: differing perspectives. J Clin Epidemiol. 1993 Oct;46(10):1075-9, discussion:1081-90.

42. Peersman G, Laskin R, Davis J, Peterson M. Infection in total knee replacement: a retrospective review of 6489 total knee replacements. Clin Orthop Relat Res. 2001 Nov;(392):15-23.

43. Ong KL, Kurtz SM, Lau E, Bozic KJ, Berry DJ, Parvizi J. Prosthetic joint infection risk after total hip arthroplasty in the Medicare population. J Arthroplasty. 2009 Sep;24(6)(Suppl):105-9. Epub 2009 Jun 2.

44. Callaghan JJ, Brand RA, Pedersen DR. Hip arthrodesis. A long-term follow-up. J Bone Joint Surg Am. 1985 Dec;67(9):1328-35.

45. Zimmerli W, Trampuz A, Ochsner PE. Prosthetic-joint infections. N Engl J Med. 2004 Oct 14;351(16):1645-54.

46. Koyonos L, Zmistowski B, Della Valle CJ, Parvizi J. Infection control rate of irrigation and débridement for periprosthetic joint infection. Clin Orthop Relat Res. 2011 Nov;469(11):3043-8.

47. Parvizi J, Azzam K, Ghanem E, Austin MS, Rothman RH. Periprosthetic infection due to resistant staphylococci: serious problems on the horizon. Clin Orthop Relat Res. 2009 Jul;:467(7):1732-9. Epub 2009 May 1.

48. Parvizi J, Pawasarat IM, Azzam KA, Joshi A, Hansen EN, Bozic KJ. Periprosthetic joint infection: the economic impact of methicillin-resistant infections. J Arthroplasty. 2010 Sep;25(6)(Suppl):103-7. Epub 2010 May 31.

49. Salgado CD, Dash S, Cantey JR, Marculescu CE. Higher risk of failure of methicillin-resistant Staphylococcus aureus prosthetic joint infections. Clin Orthop Relat Res. 2007 Aug;461:48-53.

50. Cierny G 3rd, DiPasquale D. Periprosthetic total joint infections: staging, treatment, and outcomes. Clin Orthop Relat Res. 2002 Oct;(403):23-8.

51. American Cancer Society. Cancer facts and figures 2012. 2012. http://www. cancer.org/acs/groups/content/@epidemiologysurveilance/documents/ document/acspc-031941.pdf. Accessed 2013 Jun 22.

52. Berend KR, Lombardi AV Jr, Morris MJ, Bergeson AG, Adams JB, Sneller MA. Two-stage treatment of hip periprosthetic joint infection is associated with a high rate of infection control but high mortality. Clin Orthop Relat Res. 2013

Feb;471(2):510-8.

53. Zmistowski B, Fedorka CJ, Sheehan E, Deirmengian G, Austin MS, Parvizi J. Prosthetic joint infection caused by gram-negative organisms. J Arthroplasty. 2011 Sep;26(6)(Suppl):104-8. Epub 2011 Jun 8.

54. Leung F, Richards CJ, Garbuz DS, Masri BA, Duncan CP. Two-stage total hip arthroplasty: how often does it control methicillin-resistant infection? Clin Orthop Relat Res. 2011 Apr;469(4):1009-15.

55. Marculescu CE, Cantey JR. Polymicrobial prosthetic joint infections: risk factors and outcome. Clin Orthop Relat Res. 2008 Jun;466(6):1397-404. Epub 2008 Apr 18. 56. Volin SJ, Hinrichs SH, Garvin KL. Two-stage reimplantation of total joint infections: a comparison of resistant and non-resistant organisms. Clin Orthop Relat Res. 2004 Oct;(427):94-100.

57. Quinn J, Kramer N, McDermott D. Validation of the Social Security Death Index (SSDI): An Important Readily-Available Outcomes Database for Researchers. West J Emerg Med. 2008 Jan;9(1):6-8. 